\title{
GEOGRAFIA, FOTOGRAFIA E A CONSTRUÇÃO DE CONCEITOS SOBRE O ESPAÇO URBANO: Experiências Desenvolvidas na Disciplina de Fotogeografia nos Cursos de Geografia da Ufpel
}

\author{
Maurício Meurer ${ }^{1}$ \\ Rosangela Lurdes Spironello²
}

\begin{abstract}
RESUMO
Geografia e Fotografia têm uma longa história conjunta, e ambas compartilham do interesse pela paisagem. A grande variedade de recursos atualmente disponível, fez da Fotografia uma excelente ferramenta de trabalho para geógrafos e professores de Geografia. Apesar disso, nem sempre estes profissionais têm utilizado a Fotografia para além dos aspectos estéticos, explorando questões temáticas e conceituais. Este artigo busca apresentar o relato de algumas experiências desenvolvidas na disciplina de Fotogeografia dos cursos de Geografia da Ufpel, demonstrando como a Fotografia vem sendo utilizada para o ensino de alguns temas e conceitos geográficos relevantes. Para tanto, foram realizadas diferentes propostas que incentivaram os alunos a materializar nas fotos alguns conceitos e temas abordados pela Geografia, especialmente a Geografia Urbana. Com a realização destas propostas, observou-se que o entendimento da complexidade técnica de certos procedimentos empregados na realização de algumas fotos, leva a uma valorização da Fotografia como meio artístico e de comunicação, e que muitos alunos acabam por descobrir também o potencial da Fotografia como instrumento científico, enxergando no espaço cotidiano conceitos, muitas vezes, abstratos.
\end{abstract}

Palavras-chave: Fotografia. Paisagem. Conceitos geográficos.

GEOGRAPHY, PHOTOGRAPHY AND CONSTRUCTION OF CONCEPTS ABOUT URBAN SPACE: EXPERIENCES DEVELOPED IN THE PHOTOGEOGRAPHY DISCIPLINE IN THE GEOGRAPHY COURSES OF UNIVERSITY OF PELOTAS

\begin{abstract}
Geography and photography have a long history together, and both share an interest in landscape. The wide range of resources currently available has made Photography an excellent working tool for Geographers and Geography Teachers. Nevertheless, these professionals have not always used Photography beyond its aesthetic aspects, exploring thematic and conceptual issues. This article aims to present the report of some experiences developed in the Photogeography discipline of the Geography courses of the University of Pelotas (Ufpel), demonstrating how Photography has been used to teach some relevant geographic themes and concepts. Therefore, different proposals were made that encouraged the students to materialize in the photos some concepts and themes worked by Geography, especially Urban Geography. With the realization of these proposals, it was observed that the understanding of the technical complexity of certain procedures employed in the making of some photos leads to an appreciation of Photography as an artistic and communication medium, and that many students also discover the potential of Photography as a scientific instrument, seeing in everyday space some of the concepts often abstracts.

Keywords: Photography. Landscape. Geographical concepts.
\end{abstract}

Recebido em: $12 / 2 / 2020$

Aceito em: $30 / 3 / 2020$

\footnotetext{
Graduação em Geografia pela Universidade Federal do Rio Grande do Sul (2000). Mestrado em Geografia pela Universidade Estadual de Maringá (2004). Doutorado em Geografia pela Universidade Lumière Lyon 2 (2009). Professor-associado do Departamento de Geografia da Universidade Federal de Pelotas e professor no Programa de Pós-Graduação em Geografia (Mestrado) nesta mesma universidade. Participa dos Conselhos Executivo e Consultivo da Revista Geographia Meridionalis (ISSN 24469165) e do Conselho Editorial da Revista Geográfica Acadêmica (ISSN 1678-7226). Tem experiência na prestação de serviços na área ambiental. Trabalha no domínio da Geografia Física, mais especificamente nas seguintes áreas de concentração: Geomorfologia, Geomorfologia Fluvial, Análise Ambiental. http://lattes. cnpq.br/4692042478572187. https://orcid.org/0000-0003-0007-5830. mauriciomeurer@yahoo.com.br

2 Graduação - Licenciatura em Geografia pela Universidade Federal de Santa Maria (1999). Especialização em Interpretação de Imagens Orbitais e Suborbitais (2001). Mestrado (2003) e Doutorado (2008) em Geografia (Geografia Humana) pela Universidade de São Paulo. Pós-Doutorado pela Universidade Federal de Goiás (2017). É professora-associada da Universidade Federal de Pelotas. Faz parte do Programa de Pós-Graduação em Geografia da UFPel. É membro do Grupo de Estudos Espaços Sociais e Formação Inicial e Continuada de Professores (Gesfop). Coordenadora dos cursos de Licenciatura e Bacharelado em Geografia/UFPel. Tem experiência na área de Cartografia, Cartografia Escolar, Educação de Jovens e Adultos, Educação Ambiental, Manejo Integrado de Bacias Hidrográficas. http://lattes.cnpq. br/5122075802019310.https://orcid.org/0000-0001-9272-2040.spironello@gmail.com
} 
A Geografia foi, por muito tempo, conhecida como a ciência de descrição e diferenciação dos lugares e das paisagens, e, desde esse período, as imagens já eram utilizadas como ferramenta para ilustrar estas diferenças. Nas grandes expedições dos séculos 15 e 16, muitas missões de exploração tinham, entre os seus membros, geógrafos (talvez nesta época ainda não designados formalmente como Geógrafos), a quem era confiada a tarefa de mapeamento e descrição das terras recém-descobertas. Junto a estes profissionais, estava um desenhista/pintor, responsável por capturar imagens dessas novas terras para apresentá-las nos reinos para aqueles que custeavam estas expedições. O próprio surgimento do termo paisagem remonta ao século 15 , estando associado às representações artísticas de partes da natureza, como um lance de vista a partir de uma janela, onde o "cenário" é o mais importante, e onde a representação das pessoas têm um papel secundário (CLAVAL, 2012, p. 245).

Segundo Claval (2012, p. 247), até a segunda metade do século 18 a descrição das paisagens era difícil, principalmente em razão da dificuldade de descrição das formas de relevo. Com o surgimento da fotografia, no primeiro quarto do século 19 o registro das diferenças entre as pessoas e as paisagens tornou-se relativamente mais fácil e rápido. Dada esta facilidade e a fidelidade do registro fotográfico, a fotografia passou a ser amplamente utilizada, substituindo progressivamente o trabalho de desenhistas e pintores, sendo rapidamente incorporada à Geografia como instrumento de trabalho.

Segundo Claval (2012, p. 247-248),

Os geógrafos do século XIX estão atentos à diversidade das paisagens. Seu papel é fazer com que seus leitores a descubram. Os progressos da litografia e, depois, a descoberta da fotografia facilitam sua tarefa: Humboldt se arruinou para publicar as magníficas obras ilustradas que permitiram compreender o que eram paisagens naturais e as formas de ocupação do solo da Venezuela, dos países andinos, do México e de Cuba. Por volta de 1900, os autores dispunham de meios mais eficazes para propor uma iconografia sugestiva das regiões que descreviam. A invenção do autocromo pelos irmãos Lumière, em 1908, oferece possibilidades ampliadas. O banqueiro Albert Kahn logo compreende isso e decide criar Les Archives de la Planète, fundação encarregada de enviar fotógrafos para fixar as paisagens que a modernização ameaça desnaturalizar.

Ao comentar sobre a relação entre a fotografia e a Geografia, Sidaway (2002, p. 96) afirma que

Photography and photographic images have a long history in geographical fieldwork and teaching, and through the twentieth century their role grew, to some extent displacing or complementing the traditional 'sketch' and hand-drawn map. ${ }^{3}$

Com o rápido desenvolvimento tecnológico ao longo do século 20, e com a consequente redução dos custos de produção, a fotografia, a esta altura já utilizada no ensino e na pesquisa em Geografia, evoluiu para outros tipos de representação além daquela fotografia dita "convencional": fotografia com o uso de filmes especiais (sensíveis à luz

Fotografia e imagens fotográficas têm uma longa história no trabalho de campo e no ensino geográficos, e ao longo do século 20 o papel destas cresceu de tal maneira que tomou o lugar ou complementou o tradicional "esboço" e o mapa feito à mão (Tradução do autor). 
no infravermelho, por exemplo), fotografias aéreas em pares estereográficos, que permitem uma visão tridimensional do relevo, imagens de satélite em diferentes comprimentos de onda, entre outras tecnologias que compõem o arsenal tecnológico que está disponível aos geógrafos na atualidade.

Dispondo desta variedade de recursos ao alcance da mão, será que geógrafos e professores de Geografia têm se servido da Fotografia explorando todo o potencial que este recurso pode oferecer, indo além de seu caráter estético, e investigando questões temáticas e conceituais? Teriam geógrafos e professores de Geografia métodos próprios para trabalhar com a Fotografia que os diferencie de outros profissionais?

Algumas destas questões nortearam a criação de uma disciplina optativa ofertada aos cursos de Licenciatura e Bacharelado em Geografia da Universidade Federal de Pelotas (UFPel): a disciplina de Fotogeografia. A partir da oferta desta disciplina, estratégias de ensino tiveram de ser pensadas para, entre outros objetivos, despertar nos alunos o interesse pela Fotografia, chamar a atenção para a Fotografia como uma linguagem, instrumento de ensino e pesquisa em Geografia, aprender a interpretar os fenômenos geográficos expressos nas Fotografias, e para exercitar o reconhecimento e o registro de conceitos geográficos com certo grau de abstração.

Ao falar sobre o uso de representações (tais como a Fotografia) e o domínio dos conceitos e códigos específicos da Geografia, Castellar (2019) afirma que

A Geografia apresenta o mundo pelas representações. Os mapas, imagens de satélite, fotografias e vídeos apresentam o mundo, detalhes de uma forma ou um gesto, tempos e movimentos do passado e do presente combinando-se em expressões visuais, auditivas, olfativas, palatáveis e táteis, capturadas pelos sentidos e significadas pela história individual do sujeito em contato. Apresentado ao mundo que foi e ao mundo que está sendo, o indivíduo somente pode interpretá-lo geograficamente se contar com os códigos e o vocabulário da Geografia, que são suas categorias e princípios; suas linguagens e representações e formas de raciocínio ante ao problema, condição de enfrentamento que permeia a vida do sujeito (p. 13).

Nesse contexto, o presente artigo busca apresentar o relato de algumas das experiências desenvolvidas na disciplina de Fotogeografia dos cursos de Geografia da Ufpel, demonstrando como a Fotografia vem sendo utilizada para o ensino de alguns temas e conceitos geográficos relevantes.

\section{A DISCIPLINA DE FOTOGEOGRAFIA E A CONSTRUÇÃO DE UMA PROPOSTA DE TRABALHO}

Fotogeografia é uma disciplina optativa ofertada nos cursos de Licenciatura e Bacharelado em Geografia da Ufpel. As atividades da disciplina ocorrem semanalmente, no turno da noite, em dois períodos de 50 minutos ao longo de 18 semanas. Esta disciplina tem por ementa: "Importância da observação e registro de imagens sobre o espaço geográfico. Registro fotográfico do espaço físico, social, econômico e cultural. Montagem e estruturação de imagens fotográficas. Análise e síntese do registro do espaço regional" (UFPEL, 2012, p. 187). 
São objetivos da disciplina

compreender a importância do registro fotográfico para a Geografia, registrar os aspectos físicos, sociais e econômicos do espaço geográfico, realizar a leitura e análise dos registros fotográficos e instigar o acadêmico para o uso de fotografias e imagens na perspectiva de uma leitura/releitura do espaço geográfico (UFPEL, 2012, p. 187).

Quando deu-se início à oferta da disciplina em 2009, o Departamento de Geografia ainda não dispunha de equipamentos que permitissem a realização de trabalhos práticos de Fotografia em sala de aula. Assim, as aulas eram majoritariamente teóricas, e os trabalhos práticos eram realizados, geralmente, em períodos extraclasse, com o uso dos equipamentos pessoais dos alunos e do professor. Em 2013, o Programa de Pós-Graduação em Geografia fez a aquisição de seis câmeras fotográficas do tipo bridge/ super zoom, ${ }^{4}$ marca Sony, modelo Hx300, disponibilizando estas câmeras ao Departamento de Geografia para uso compartilhado. Desde então, estas câmeras passaram a ser utilizadas para as aulas teóricas e para as atividades práticas da disciplina.

O programa da disciplina foi estruturando-se ao longo dos anos, buscando sempre combinar conteúdos de Fotografia e de Geografia, e procurando pelos pontos de contato entre estas duas áreas. Atualmente, este programa vem sendo trabalhado em três unidades distintas.

Na primeira unidade, os alunos têm aulas teóricas e práticas sobre Fotografia. Entre os conteúdos trabalhados, estão os princípios da fotografia, o funcionamento das câmeras fotográficas, os ajustes básicos da câmera fotográfica, os elementos da fotografia, os princípios e regras de composição, profundidade de campo, além de várias técnicas criativas e tipos de fotografia (fotografias de longa exposição, fotografias em contraluz, still, macro, panning, grafismos e minimalismo).

Na segunda unidade, são trabalhadas questões de Geografia que auxiliem na compreensão da representação da paisagem e do espaço urbano. Nesse momento, tem-se trabalhado com o capítulo 5 do livro Metamorfoses do Espaço Habitado (SANTOS, 2012), que aborda questões teórico-conceituais sobre Paisagem e Espaço, com os conceitos de Topofilia e Topofobia propostos por Tuan (1974), com metodologias de análise da paisagem urbana, tais como a visão serial da paisagem e a análise da paisagem urbana (CULLEN, 1983 apud ADAM, 2008), e a leitura da paisagem a partir de fotografias (COELHO, 2011).

$\mathrm{Na}$ terceira unidade, trabalha-se com a construção de um projeto Fotogeográfico, que, além de servir como avaliação da disciplina, é exposto ao término do semestre. Para embasar este projeto, são apresentados aos alunos alguns materiais que possam orientá-los e inspirá-los na construção das propostas. Entre os materiais apresentados, estão o livro de fotografias do renomado geólogo/geógrafo João José Bigarella (2003),

Bridge/superzoom: de acordo com Regina e Takazaki (2015, p. 15), "são câmeras consideradas como meio termo entre as de bolso e profissionais. Sua maior vantagem é possuir mais configurações personalizáveis garantindo bastante controle", sendo muito versáteis. É comum que este tipo de câmera possua zoom ótico de grande magnitude, sendo, por isso, chamadas de superzoom. 
o livro com as fotos participantes do concurso Géophoto (ESRI, 2015) e o Guia de Fotojornalismo da National Geographic Marcopolo Xpeditions (NATIONAL GEOGRAPHIC SOCIETY, 2005).

\section{A METODOLOGIA DE AVALIAÇÃO: OS ENSAIOS FOTOGEOGRÁFICOS}

Ao longo dos últimos dez anos, período em que a disciplina de Fotogeografia vem sendo ofertada com regularidade, diferentes propostas de avaliação final foram apresentadas aos alunos da disciplina, de maneira a orientá-los para a realização dos ensaios Fotogeográficos.

Uma das primeiras propostas tinha como tema "Fotogeografia de Pelotas: um olhar geográfico sobre o espaço cotidiano". Nesta proposta, uma lista com os seguintes conceitos e temas, frequentemente trabalhados pela Geografia Urbana, foi apresentada aos alunos:

- Expansão/Retração Urbana;

- Centralização/Descentralização;

- Exclusão/Segregação/Autosegregação/Marginalidade;

- Gentrificação;

- Identidade e Resistência;

- Territórios;

- Verticalização/Horizontalização;

- Redes;

- Não lugar;

- Espaços Públicos/Privados;

- Funções Urbanas;

- Conflitos entre os produtores do espaço urbano.

Em grupos, os alunos deveriam optar por um dos conceitos ou temas desta lista para, em seguida, procurar retratá-lo no espaço urbano da cidade de Pelotas. O resultado final deveria ser entregue sob a forma de um memorial descritivo, com uma apresentação do tema, e de um banner, com, no mínimo, quatro fotos, que seria exposto em um local de grande circulação no prédio do Instituto de Ciências Humanas da universidade.

A construção desta proposta buscou desafiar os alunos a encontrar, materializados na paisagem urbana da cidade de Pelotas, alguns conceitos e temas comumente presentes na literatura, mas que nem sempre são de fácil compreensão e representação. Muitos conceitos sobre espaço, paisagem e território, tradicionais categorias de análise da Geografia, estão claramente expressos na paisagem da maioria das cidades. Segundo Sanders (2007, p. 183), "Geographical concepts almost always represent themselves as ideal types and have signature imprints that are recognizable even on the small neighborhood scale".${ }^{5}$ Isso nos mostra que não é necessário estar em uma grande metrópole para desenvolver um trabalho baseado na busca da materialidade destes conceitos.

Os conceitos geográficos quase sempre apresentam-se como tipos ideais e possuem marcas de assinatura que são reconhecíveis até mesmo na pequena escala de vizinhança (Tradução do autor). 
Ao propor um trabalho que demanda o registro da materialização de conceitos no espaço urbano, os alunos devem, primeiramente, compreender os conceitos e depois pensar sobre as possíveis formas como estes podem estar materializados (de maneira explícita ou implícita) na paisagem urbana, para, finalmente, partirem na busca dos registros fotográficos. De acordo com Sanders (2007, p. 186), independente de esta busca ocorrer no espaço cotidiano, nem sempre ela é fácil para o olhar destreinado:

Concepts such as social exclusion/marginality, community (disintegration), gentrification, identity, and new urbanism feature prominently in urban social geography. Moreover, they ground themselves on the landscape and can be captured by the trained, observant eye. ${ }^{6}$

Em um trabalho que também utilizou a fotografia como instrumento de mediação para o ensino de Geografia, Nunes (2016) chama a atenção para a importância dessa etapa de identificação e construção de conceitos pelos alunos. A autora ressalta a relevância da utilização e aplicação desses conceitos pelos alunos ao mundo real, de maneira similar ao que foi proposto aos alunos da disciplina de Fotogeografia da UFPel,

... a apropriação da linguagem geográfica se dá a partir da construção de conceitos e habilidades que possibilitam ao aluno ler o espaço, mediado pela compreensão dos elementos que o compõem, bem como pela lógica de construção deste, que será apreendida por meio da utilização e aplicação dos conceitos à realidade.

Desta forma, além da construção dos conceitos geográficos, que podem ser trabaIhados desde o início do processo de alfabetização, é necessário desenvolver habilidades que capacitem o aluno a se apropriar de tais conceitos (NUNES, 2016, p. 33).

No ano de 2017, uma segunda proposta de avaliação final foi apresentada aos alunos da disciplina. Desta vez, ao invés de dar aos alunos uma lista de conceitos pré-selecionados, foi passado à turma um conjunto de quatro artigos sobre diferentes questões urbanas (COSTA, 2012; SERPA, 2013; GARCIA, 2017; PARRA; PASSARELLI, 2017). Os alunos foram, então, orientados a tentar identificar nestes artigos alguns conceitos ou temas pertencentes à Geografia que pudessem ser ilustrados por meio de um ensaio fotogeográfico. A seguir, um projeto de ensaio deveria ser redigido, fundamentando o conceito escolhido. Por fim, os alunos deveriam realizar os registros fotográficos em campo e organizar um material para exposição. Vale destacar que, desde este ano, dado o aumento dos custos de impressão, deixou-se de exigir a elaboração de um banner, possibilitando aos alunos a escolha da forma de apresentação do resultado final.

Em 2018, a avaliação final da disciplina foi feita de maneira mais aberta. Delimitou-se apenas que esta deveria ser baseada em conceitos ou temas relacionados à Geografia Urbana, sem passar aos alunos uma lista de conceitos pré-selecionados ou um conjunto de artigos para extrair dali os conceitos para o trabalho. Assim como já havia

Conceitos como exclusão social/marginalidade, comunidade (desintegração), gentrificação, identidade e novo urbanismo, aparecem com destaque na geografia social urbana. Além disso, eles estão expressos na paisagem e podem ser capturados pelo olho treinado e observador. 
ocorrido no ano anterior, o trabalho foi apresentado na forma escrita, com a fundamentação conceitual do tema a ser trabalhado no ensaio fotogeográfico, e na forma de material para exposição, novamente sem a obrigatoriedade de uso do formato banner.

\section{RESULTADOS}

Ao longo destes dez anos em que a disciplina de Fotogeografia vem sendo ofertada, a realização destes ensaios fotogeográficos tem permitido observar algumas questões interessantes sobre a relação dos alunos com a Fotografia e a Geografia.

Desde o início da disciplina, foi possível observar a dificuldade que a maior parte dos alunos tem ao lidar com um tema do domínio das artes, quando as questões subjetivas, como a percepção e os sentimentos, são tão importantes quanto as questões mais cartesianas, como as de regulagem da câmera fotográfica, por exemplo. Ao tratar de temas como "Os Elementos da Fotografia" e "Princípios da Composição", inevitavelmente trabalha-se com os sentimentos e percepções dos observadores ante a fotografias com diferentes elementos e composições. A aceitação dos alunos quanto ao fato de as fotografias serem organizadas e pensadas para causarem determinados sentimentos ao observador, nem sempre é imediata, sendo uma ideia que precisa ser trabalhada ao longo de toda a disciplina.

Esta dificuldade que os alunos apresentam em trabalhar com questões artísticas tem reflexo nos trabalhos práticos. Ao fazerem os registros fotográficos, os alunos nem sempre conseguem desvencilhar-se do registro fotográfico "tradicional" (aquele registro em que simplesmente aponta-se a câmera para a frente, enquadra-se o objeto desejado e executa-se o disparo). Poucos alunos arriscam-se a registros fotográficos menos convencionais, mais ousados técnica, estética ou artisticamente. Ao longo do semestre, tenta-se encorajá-los a, progressivamente, sair da obviedade, do lugar-comum, do pensamento cartesiano, e a se arriscar a realizar exercícios fotográficos fora de sua zona de conforto.

A partir da realização das diferentes avaliações finais propostas, outras questões foram tornando-se mais evidentes. Uma delas é a dificuldade que os alunos têm para realizar o planejamento dos projetos fotogeográficos. No geral, logo após a proposição da avaliação final, os grupos costumam passar por um período de muitas dúvidas, não sabendo o que propor como tema para o ensaio e nem por onde começar o planejamento. É natural, também, que as propostas iniciais sejam obviedades, temas de senso comum, e quase sempre de pouco embasamento teórico. Para tentar auxiliar nesta etapa, é normal que os grupos tenham de receber orientação do professor.

Uma das questões que auxilia no entendimento dessa dificuldade de propor e planejar os ensaios é a necessidade de trabalhar com conceitos. Por mais que a literatura possa já trazer os conceitos previamente definidos, há a necessidade de decodificá-los, assimilá-los, interpretá-los, para, posteriormente, buscá-los na paisagem. Como já exposto anteriormente por Sanders (2007, p. 186), é preciso ter o olhar treinado para enxergar os conceitos na paisagem urbana, e não se chega a este olhar em um curto período de tempo. 
Essa dificuldade de transposição dos conceitos geográficos para a realidade, torna-se evidente no resultado de alguns trabalhos, quando os alunos não conseguem representar de maneira apropriada certos conceitos, sobretudo aqueles mais complexos e abstratos, ou quando há associações demasiadamente simplistas ou equivocadas entre imagem, conceito e legendas das fotografias.

Apesar de ser uma das intenções da disciplina, nem sempre os alunos compreendem a Fotografia como um possível instrumento de pesquisa, de onde é possível, inclusive, extrair alguns dados. Para muitos, a fotografia em pesquisa está restrita a um papel ilustrativo, o que não é necessariamente correto.

Assim, busca-se mudar esta visão equivocada com a apresentação de alguns trabalhos que têm na Fotografia a sua principal fonte de dados, como o método Observatório Fotográfico da Paisagem (OPP) (FRANÇA, 2008), a construção e aplicação de um método para o estudo da paisagem por meio de fotografias (COELHO, 2011), ou dois estudos aplicados mediante o uso de fotografias para a definição do melhor percurso para o caminho de Santiago de Compostela (GRISELIN; NAGELEISEN, 2003) e para o monitoramento sazonal da superfície de mar congelado no Ártico (GRISELIN; NAGELEISEN; ORMAUX, 2005).

Apesar de todas as dificuldades apresentadas, o desenvolvimento dos projetos fotogeográficos na disciplina de Fotogeografia tem apresentado resultados interessantes. Foram selecionados alguns exemplos, que serão expostos e comentados a seguir.

No ano de 2012, um grupo de alunos selecionou da lista de conceitos o tema "Espaço Público x Espaço Privado". Sobarzo (2006, p. 96) afirma que "...a distinção entre público e privado ficou restrita ao patrimônio público e ao patrimônio privado, à esfera da propriedade e não dos direitos das pessoas". Nesse sentido, o autor esclarece, ainda, que "Essa falta de diferenciação clara do público e do privado significa, do ponto de vista da dominação política, a invasão da esfera do público pelo privado, no intuito de reproduzir, ampliar e/ou consolidar as relações de poder".

Para ilustrar o conflito entre estes espaços, o grupo fez uma foto do antigo camelódromo de Pelotas (Figura 1), e mostrou, de maneira muito evidente, o avanço das bancas e mercadorias sobre o espaço público de circulação de pedestres. Na posição quase ao centro da fotografia, uma perspectiva é criada por esta área coberta repleta de mercadorias, e predominam os tons escuros na parte interna desta perspectiva, dando ao observador a noção de falta de espaço e má iluminação. Vale lembrar, ainda, que pouco tempo após a realização desse registro o camelódromo de Pelotas foi destruído, dando lugar ao shopping center popular (Pop Center). 
Figura 1 - Registro fotográfico feito para o trabalho sobre "Espaço Público x Espaço Privado", mostrando o avanço do comércio sobre o espaço público de circulação de pedestres

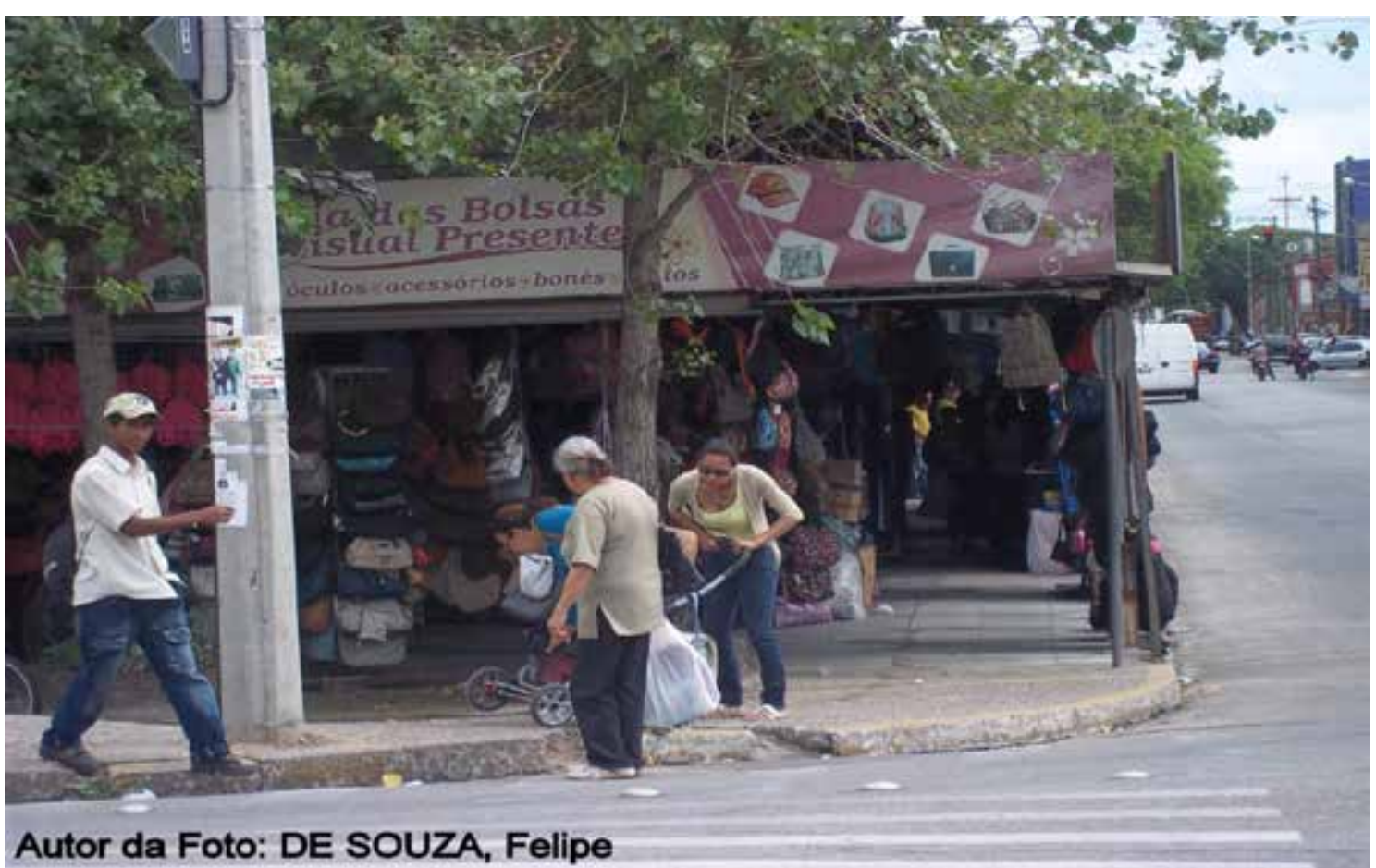

Foto: Felipe de Souza (2012).

No ano de 2017, a partir da leitura dos artigos indicados, um dos grupos optou por abordar o tema "Mobilidade urbana em São Lourenço do Sul - RS".

Este trabalho foi desenvolvido no município de São Lourenço do Sul, distante cerca de $65 \mathrm{~km}$ de Pelotas, e de onde a Ufpel costuma receber muitos alunos. Apesar do tema em si não ser surpreendente ou original, a fotografia apresentada (Figura 2) destaca-se tanto pelo incomum meio de transporte retratado quanto pela iluminação diferenciada, que deu à fotografia um ar "envelhecido". Analisando a composição realizada, chama atenção a posição da via, que vai da diagonal inferior esquerda até a metade da lateral direita da foto, fazendo o olhar do observador guiar-se por essa linha e atravessar todo o enquadramento. O objeto principal da foto (essa espécie de bicicleta) ocupa uma posição levemente deslocada à esquerda, com bastante espaço à sua frente para dar ao observador a noção de área livre para deslocamento. Próximo da margem direita da composição, um carro encontra-se no limite do enquadramento, fazendo um contraponto com a bicicleta e deixando ao observador a liberdade de imaginar o que há na continuidade da via.

Trabalhar o conceito de mobilidade urbana na Geografia traz discussões interessantes que vão além do entendimento de mobilidade como formas de deslocamento. Passa-se a entender e debater a mobilidade também como possibilidade de uso dos diferentes espaços de vivência, como o acesso "...às oportunidades e às funções econômicas, culturais e sociais das cidades, possibilitando a todos a satisfação individual e coletiva de atingir os destinos desejados, necessidades, prazeres e realizações cotidianas (SILVA, 2016, p. 299). 
Figura 2 - Registro fotográfico feito para o trabalho sobre "Mobilidade urbana em São Lourenço do Sul-RS", mostrando o uso de diferentes meios de transporte no município

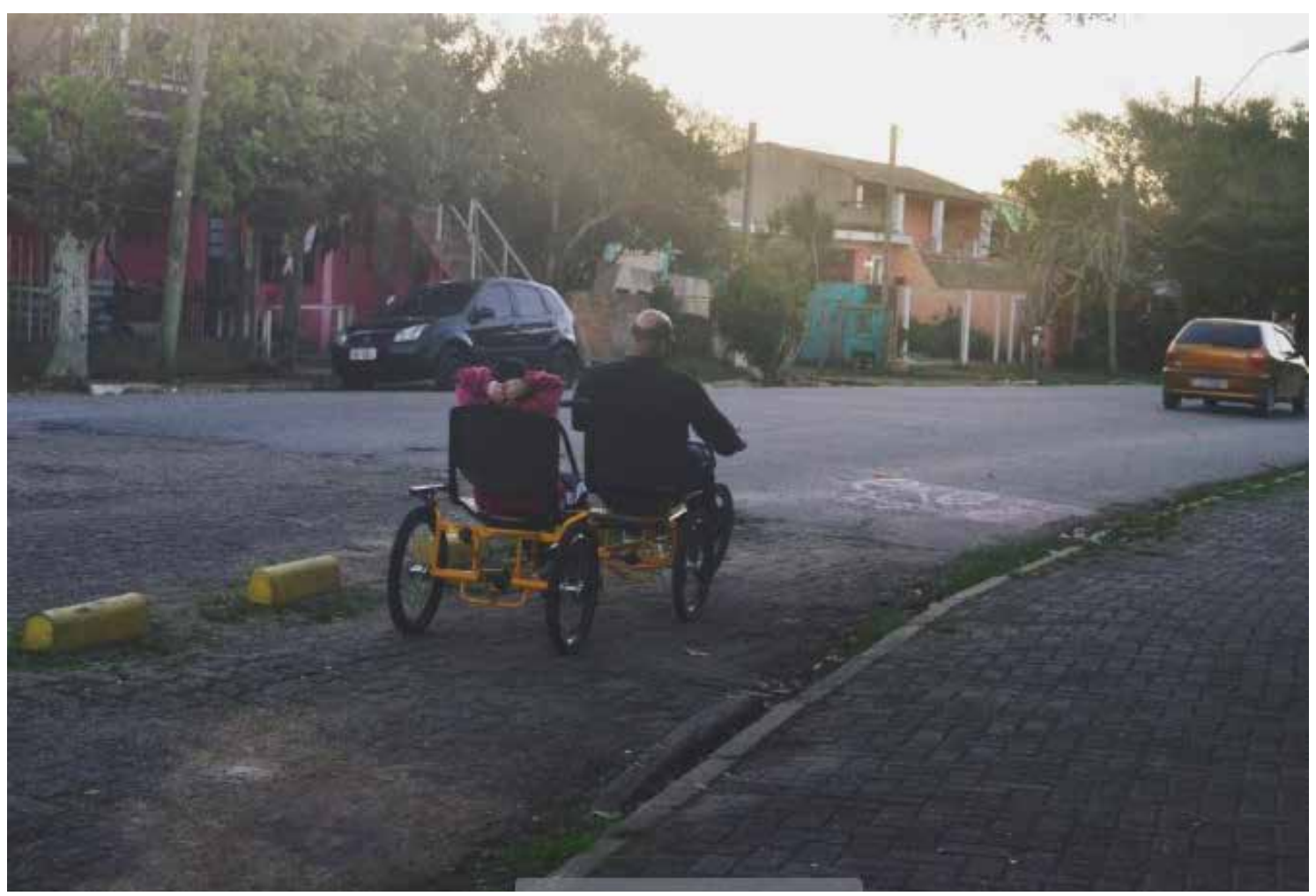

Foto: Bruna Vieira (2017)

No ano de 2018, quando os trabalhos foram realizados de maneira mais aberta, sem a indicação prévia de conceitos ou de bibliografia, um dos grupos apresentou a proposta de trabalhar sobre "As Inércias de Pelotas", utilizando, para isso, o conceito de inércia, que traduz a permanência de certas formas e usos no espaço urbano, mesmo já tendo cessado aquilo que motivava a existência destas formas e usos. Nas fotografias apresentadas pelo grupo, duas, em especial, chamaram a atenção: na primeira (Figura 3), observa-se foto da fachada do antigo Teatro Avenida. Apesar da composição não merecer grande destaque, é inevitável fazer o contraponto entre a fachada arquitetonicamente rebuscada do antigo teatro e o seu atual estado de abandono. Em posição de destaque, uma grande faixa de "vende-se" sobressai-se da fachada acinzentada, deixando implícita a atuação dos agentes do mercado imobiliário como produtores do espaço urbano. Na segunda fotografia (Figura 4), observa-se a fachada do Teatro Sete de Abril. Ao contrário da fotografia do Teatro Avenida, esta foto do Teatro Sete de Abril apresenta uma composição com viés mais artístico, que foge do usual. A fotografia foi tomada de baixo para cima, utilizando a estrutura da marquise da entrada como um elemento geométrico em primeiro plano, tendo ao fundo a fachada do teatro em perspectiva. Outros elementos chamam a atenção do observador nesta foto: as plantas presas na estrutura metálica da marquise (que passam a ideia de falta de manutenção), os altos prédios que ladeiam o teatro, mostrando novamente a pressão dos produtores do espaço urbano sobre este local, e uma pomba, que, por mero acaso, aparece em voo com asas bem abertas, que quebra a simetria da foto e traz a esta uma certa peculiaridade. 


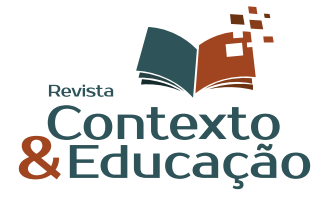

Geografia, Fotografia e a Construção de Conceitos Sobre o Espaço Urbano:

Experiências Desenvolvidas na Disciplina de Fotogeografia nos Cursos de Geografia da Ufpel

Figura 3 - Registro fotográfico feito para o trabalho sobre "As Inércias de Pelotas". Na foto, observa-se a fachada do antigo Teatro Avenida

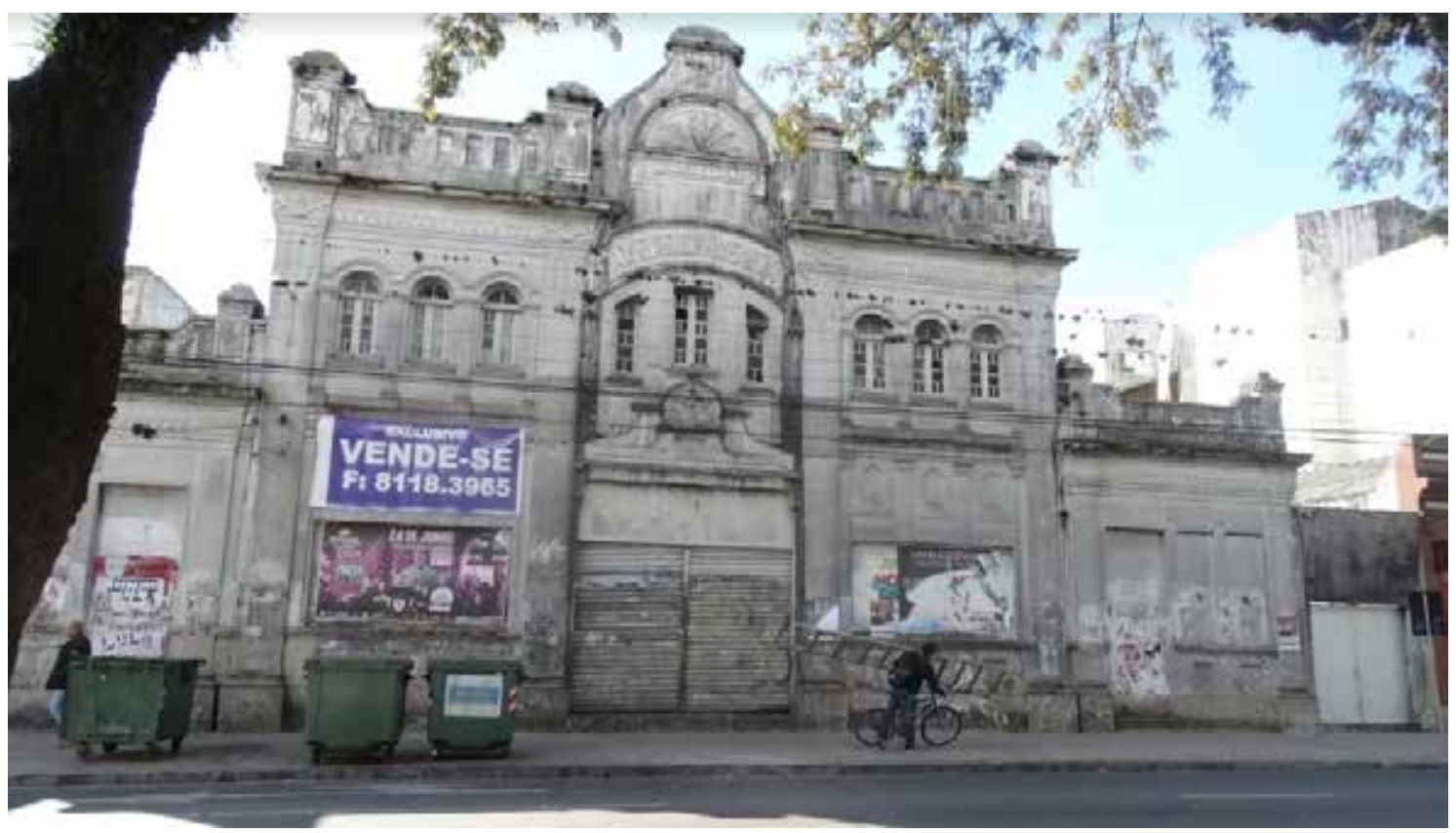

Foto: Kelvin Xavier (2018).

Figura 4 - Registro fotográfico feito para o trabalho sobre "As Inércias de Pelotas". Na foto, observa-se uma composição mais artística para o registro da fachada do Teatro Sete de Abril

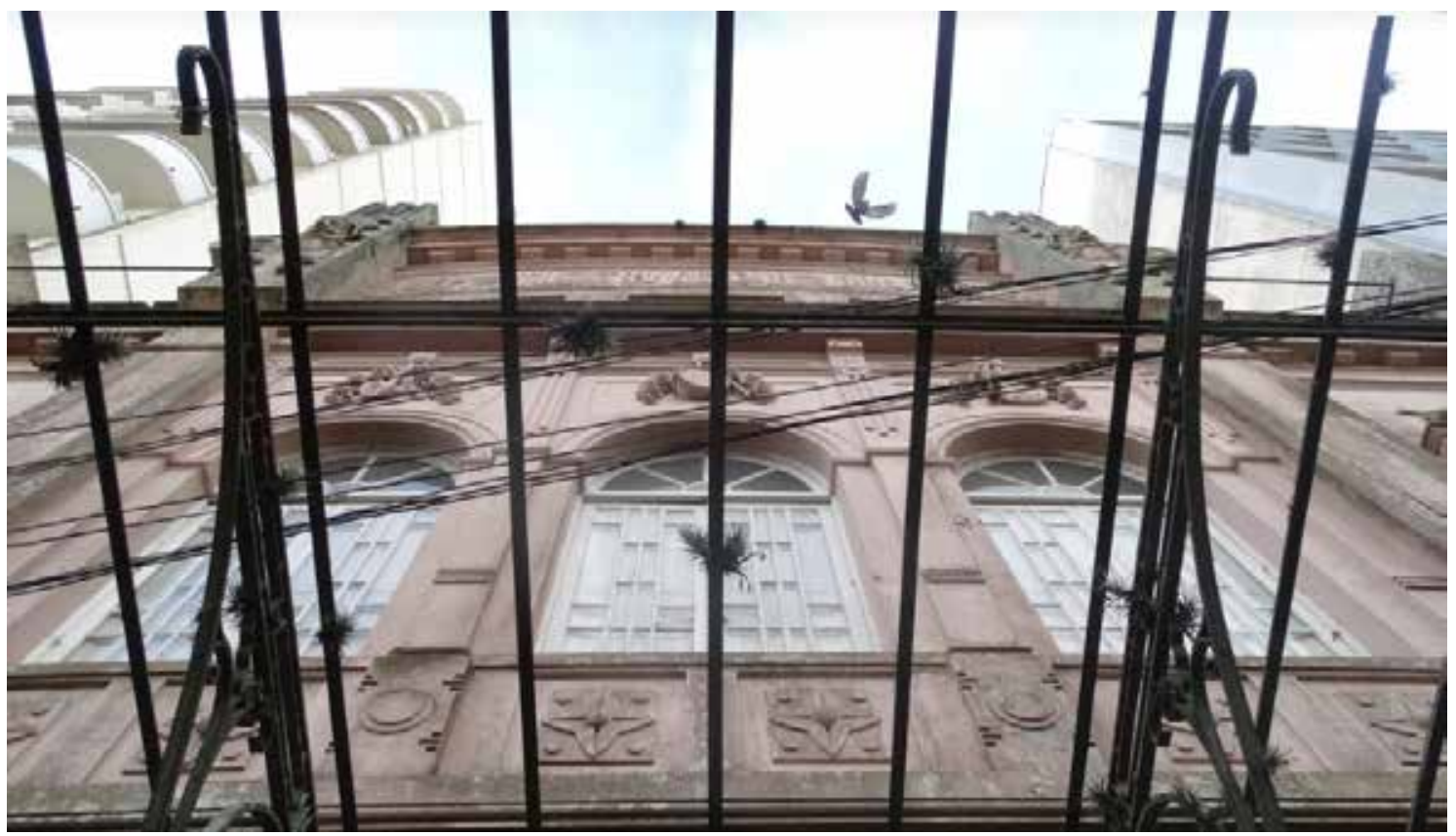

Foto: Vanessa Prestes (2018).

Ainda em 2018, um grupo trabalhou o tema "Funções e Sentimentos no centro urbano de Pelotas/RS", quando procurou trabalhar com os conceitos de topofilia e topofobia estabelecidos por Tuan (1974). As fotos foram realizadas com base em uma pesquisa previamente aplicada pelo grupo, em que buscavam identificar quais lugares na 
área central de Pelotas os entrevistados diziam ter prazer em frequentar, e quais lugares os entrevistados evitavam frequentar. Entre as muitas fotos apresentadas neste trabaIho, duas merecem destaque. A primeira (Figura 5) é um registro feito na Praça Coronel Pedro Osório, principal praça de Pelotas. Na foto, é possível ver parte da esplanada central da praça, onde encontra-se a o chafariz Fonte das Nereidas. No primeiro plano, à direita, sentadas nos degraus que levam ao chafariz, três moças com ar descontraído conversam e tomam chimarrão. Ao fundo, sentadas em um banco, mais duas mulheres conversam e descansam. Isoladamente, esta fotografia não mostra nada que a torne especial, porém, quando analisada junto com a outra fotografia apresentada pelo grupo, ambas conversam diretamente com o tema central do trabalho. A segunda foto do grupo (Figura 6) mostra a Praça Cipriano Barcelos, outra importante praça no centro de Pelotas. Esta encontra-se afastada cerca de 4 quadras (aproximadamente 400 metros) da Praça Coronel Pedro Osório, local da primeira foto. Na fotografia da Praça Cipriano Barcelos, um banco vazio, no primeiro plano, e a ausência de pessoas nos planos subsequentes, passam ao observador a sensação de local pouco frequentado e/ou evitado pela população. A partir da realização deste trabalho, estas duas fotografias levaram os alunos a fazer a seguinte reflexão: Por que duas praças tão próximas, com muitas semeIhanças entre si, acabam por causar sensações opostas na população de Pelotas?

Figura 5 - Registro fotográfico feito para o trabalho sobre "Funções e Sentimentos no centro urbano de Pelotas/RS". A foto mostra pessoas em atividades de lazer na Praça Coronel Pedro Osório, remetendo ao conceito de topofilia

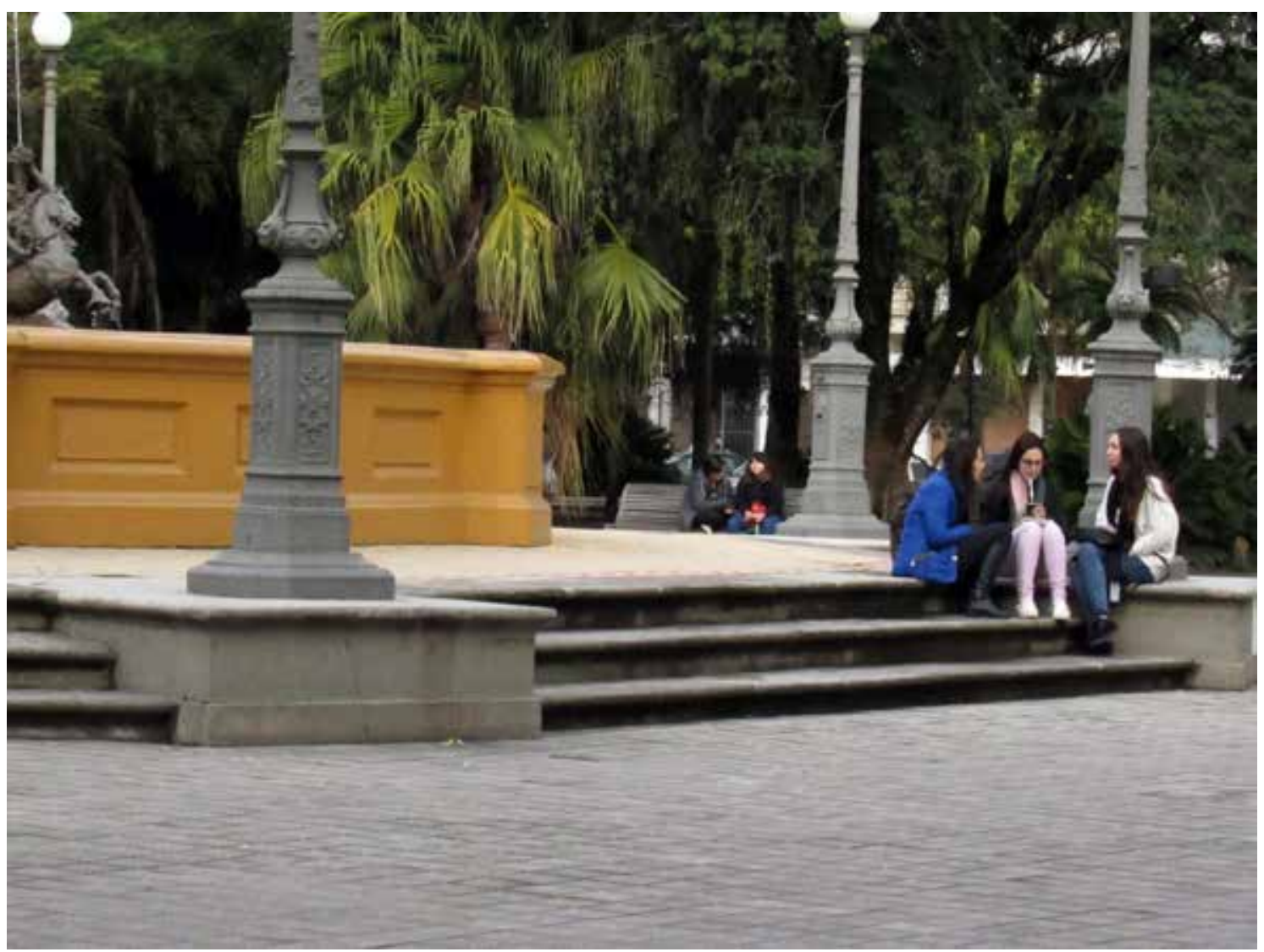

Foto: Nathália Bonow (2018). 
Figura 6 - Registro fotográfico feito para o trabalho sobre "Funções e Sentimentos no centro urbano de Pelotas/RS". A foto mostra um banco vazio e o estado de má conservação da Praça Cipriano Barcelos, remetendo ao conceito de topofobia

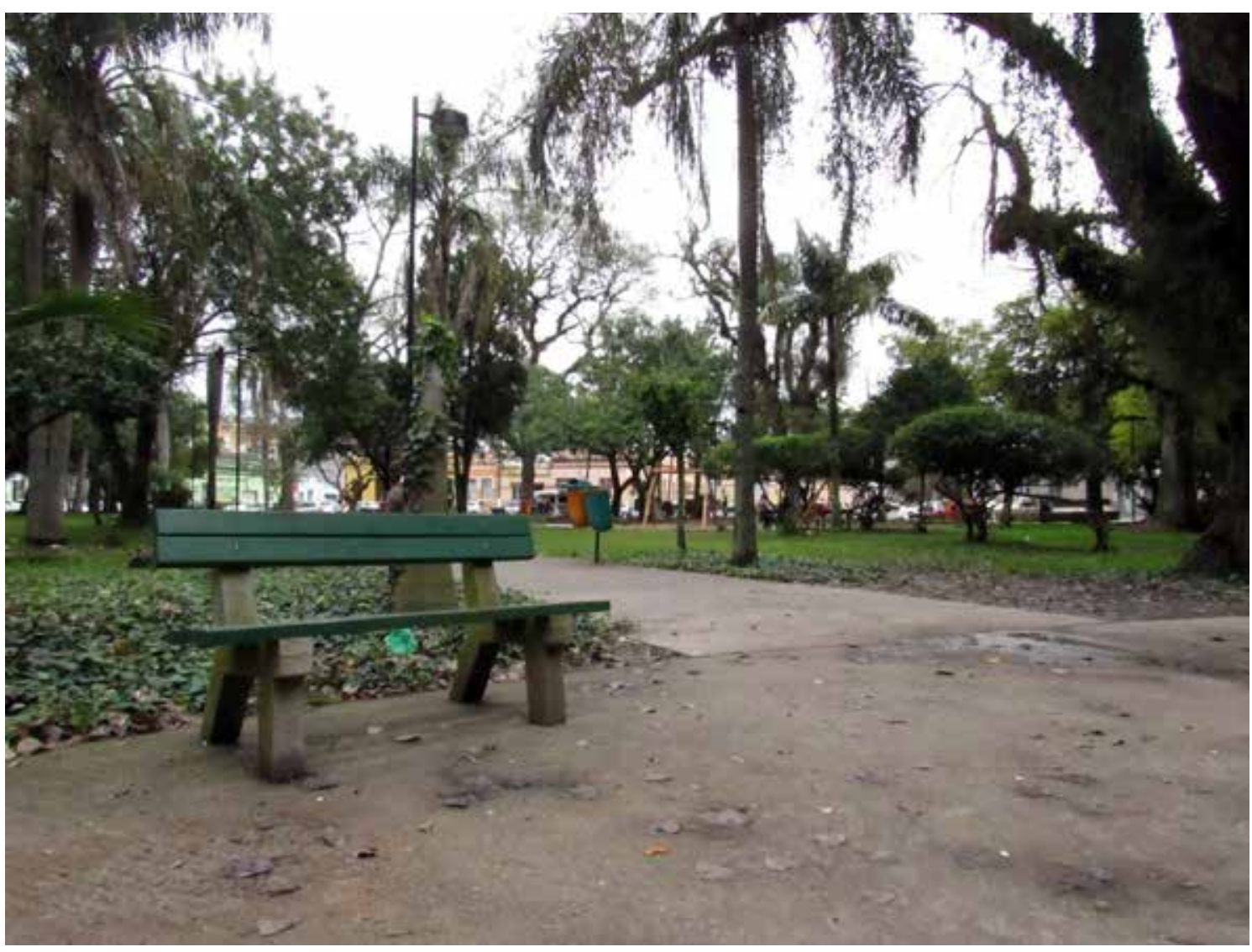

Foto: Nathália Bonow (2018).

\section{CONCLUSÕES}

Ao longo destes dez anos em que vem sendo ofertada, a disciplina de Fotogeografia tem buscado mostrar aos alunos, por intermédio de suas aulas teóricas e atividades práticas, o potencial da Fotografia como instrumento de pesquisa em Geografia.

Para alguns alunos, a disciplina tem funcionado como um ponto de partida para descobrir a Fotografia como linguagem e como arte, com suas diferentes correntes artísticas, técnicas de execução, percepções e sensações. Observa-se que, ao término da disciplina, o entendimento da complexidade técnica de certos procedimentos empregados na realização de algumas fotos, leva a uma valorização da Fotografia como meio artístico e de comunicação. Por outro lado, ao longo da disciplina muitos alunos acabam por descobrir também o potencial da Fotografia como instrumento científico, capaz de levantar pontos de partida para discussão, de ilustrar conceitos e processos, de representar fenômenos e intenções e de possibilitar, inclusive, o levantamento de dados qualitativos e quantitativos.

Apesar das dificuldades mencionadas, a proposta de avaliação por meio dos ensaios fotogeográficos tem sido uma etapa extremamente importante da disciplina. 0 planejamento e o desenvolvimento destes ensaios exercita nos alunos uma série de ha- 
bilidades, tais como a montagem de projetos, o domínio de conceitos e temas pertinentes para a Geografia, o reconhecimento da materialização dos conceitos no espaço, o uso de fotografias e de técnicas de comunicação visual, entre outras.

Sanders (2007, p. 185) afirma que "(the picture) it is a powerful tool in examining the sociospatial dialectic". ' Mediante a disciplina de Fotogeografia, os alunos têm conseguido visualizar, no espaço urbano de Pelotas, alguns conceitos, por vezes, abstratos. Aos poucos, além dos conceitos, os alunos vão reconhecendo também as forças que se opõem na dialética socioespacial deste espaço cotidiano, e que anteriormente passavam despercebidas. Dominar os conceitos teóricos de sua área de atuação e ter a capacidade de visualizar as contradições do espaço, são habilidades essenciais aos futuros professores de Geografia e Geógrafos, e os trabalhos desenvolvidos pela disciplina de Fotogeografia têm contribuído para que estas habilidades sejam exercitadas.

\section{REFERÊNCIAS}

ADAM, R. S. Analisando o conceito de paisagem urbana de Gordon Cullen. Da Vinci, Curitiba, v. 5, n. 1, p. 61-68, 2008.

BIGARELLA, J. J. Nas trilhas de um geólogo: paths of a Geologist. Curitiba: Imprensa Oficial, 2003.

CASTELLAR, S. M. V. Raciocínio geográfico e a teoria do reconhecimento na formação do professor de geografia. Signos Geográficos, Goiânia: UFG, v. 1, p. 1-20, 2019.

CLAVAL, P. A paisagem dos geógrafos. In: CORRÊA, R. L.; ROSENDAHL, Z. (org.). Geografia cultural: uma antologia. Rio de Janeiro: Eduerj, 2012. 344p. V. 1.

COELHO, L. C. Revelando a paisagem através da fotografia: construção e aplicação de um método - Porto Alegre vista do Guaíba. 2011. 313 p. Dissertação (Programa de Pós-Graduação em Planejamento Urbano e Regional), Porto Alegre: UFRGS, 2011.

COSTA, E. B. da. Intervenções em centros urbanos no período da globalização. Cidades, v. 9, n. 16, p. 86117,2012

CULLEN, G. Paisagem urbana. São Paulo: Martins Fontes, 1983.

ESRI. Géophotos, le recueil 2015: quand la géographie rencontre la photographie. Paris: Esri, 2015. 60 p. GARCIA, C. G. Cultura e cidade: novas configurações socioespaciais na era pós-industrial. ENANPUR, 17., 2017, São Paulo. Anais [...]. São Paulo, 2017. 13p.

GRISELIN, M.; NAGELEISEN, S. "Quantifier» le paysage au long d'un itinéraire à partir d'un échantillonnage photographique au sol. 6èmes Rencontres de Théo Quant, Besançon, França 20-21, fev. 2003. Disponível em: http://cybergeo.revues.org/3684\#tocto2n2.

GRISELIN, M.; NAGELEISEN, S.; ORMAUX, S. La photographie oblique terrestre pour une veille environnementale en milieu arctique 7ème Rencontres de Théo Quant. França, jan. 2005, p. 2-13. Disponível em: http://thema.univ-fcomte.fr/theoq/pdf/2005/TQ2005\%20ARTICLE\%2014.pdf.

FRANÇA. Itinéraires Photographiques: méthode de l'Observatoire Photographique du Paysage. Paris: Ministère de l'Écologie, de l'Énergie, du Développement durable et de l'Aménagement du territoire, 2008. 74p.

NATIONAL GEOGRAPHIC SOCIETY. National Geographic Marcopolo Xpeditions Photojournalism Guide (68). Washington D. C.: National Geographic, 2005. 4 p.

NUNES, F. G. Linguagem fotográfica e ensino de geografia: experiências desenvolvidas no PIBID/Geografia/UFGD. Revista PerCursos, Florianópolis, v. 17, n. 35, p. 28-48, set./dez. 2016.

PARRA, A.; PASSARELLI, S. H. Dinâmicas culturais populares em centros urbanos: barreiras e motivações. ENANPUR, 17., 2017, São Paulo. Anais [...]. São Paulo, 2017. 20 p.

REGINA, C.; TAKAZAKI, S. Dicas de fotografia. 1. ed. Rio de Janeiro: Claudia Regina, 2015. 309 p.

SANDERS, R. Developing Geographers through Photography: Enlarging Concepts. Journal of Geography in Higher Education, v. 31, n. 1, p. 181-195, jan. 2007.

"(a fotografia) é uma poderosa ferramenta no exame da dialética socioespacial". (Tradução do autor). 


\section{\& Contexto}

Geografia, Fotografia e a Construção de Conceitos Sobre o Espaço Urbano:

SANTOS, M. Metamorfoses do espaço habitado: fundamentos teóricos e metodológicos da geografia. 6. ed. 1a reimpr. São Paulo: USP, 2012.

SERPA, A. Microterritórios e segregação no espaço público da cidade contemporânea. Cidades, v. 10, n. 17, p. 61-75, 2013.

SIDAWAY, J. D. Photography as Geographical Fieldwork. Journal of Geography in Higher Education, v. 26, n. 1, p. 95-103, 2002.

SILVA, A. da. Mobilidade urbana e equidade social: possibilidades a partir das recentes políticas de transporte público na Metrópole do Rio de Janeiro. In: Geografia e Ordenamento do Território, Revista Electrónica, Centro de Estudos de Geografia e Ordenamento do Território, n. 10, p. 293-317, 2016.

SOBARZO, O. A produção do espaço público: da dominação à apropriação. In: GEOUSP, Espaço e Tempo Revista de Pós-Graduação/Departamento de Geografia, São Paulo: Faculdade de Filosofia, Letras e Ciências Humanas, Universidade de São Paulo, FFLCH/USP, n· 19, p. 93-111, 2006.

TUAN, Y-F. Topofilia: um estudo da percepção, atitudes e valores do meio ambiente. São Paulo: Difel, 1974. 288 p.

UFPEL. PPP - Projeto Político Pedagógico do Curso de Bacharelado em Geografia. Pelotas: UFPel, 2012. $205 \mathrm{p}$. 